\title{
Yurtdışında Kimya Doktorası Yapan Türklere Ek
}

\section{Addenda to the First Turkish PhD Recipients in Chemistry}

\section{Şeref Etker ${ }^{1}$ (1)}

Dr., İstanbul, Türkiye

ORCID: Ş.E. 0000-0001-6966-8816

Sorumlu yazar/Corresponding author:

Şeref Etker, İstanbul, Türkiye

E-posta/E-mail: serefetker@gmail.com

Başvuru/Submitted: 01.12 .2019

Kabul/Accepted: 02.12 .2019

Online Yayın/Published Online: 03.01.2020

Atıf/Citation:

Etker, Şeref. "Yurtdışında Kimya Doktorası Yapan Türklere Ek." Osmanlı Bilimi Araştırmaları 21, 1 (2020): 201-203. https://doi.org/10.26650/oba.653712

Osmanlı Bilimi Araştırmaları'nda yayımlanan “Prof.Dr. Remziye Hisar'ın Anıları ve Görüşlerini İçeren Bir Kitap Hakkında Düşünce ve Katkılar” başlıklı yayın tanıtımı içinde, ${ }^{1}$ Erdal İnönü’nün Türkiye Kimya Araştırmaları Bibliyografyası kaynak gösterilerek, 2 " "1940 öncesinde Avrupa'nın çeşitli ülkelerinde Türklerin yaptığı kimya doktoraları” bir tabloda özetlenmiştir (Çizelge 1). Buna göre, 1876-1918 yılları arasında altı Türk, Avrupa üniversitelerindeki çalışmalarıyla kimya doktoru olmuşlardır. Yurtdışında doktora yapan ilk kimyager-eczacı Joseph Zanni' dir (Hovsep Papazyan, 1854-1934). ${ }^{3}$

1 Emre Dölen, "Prof.Dr. Remziye Hisar'ın Anıları ve Görüşlerini İçeren Bir Kitap Hakkında Düşünce ve Katkılar," Osmanlı Bilimi Araştırmaları 20, 2 (2019): 133-145.

2 Erdal İnönü, 1923-1966 Dönemi Türkiye Kimya Araştırmaları Bibliyografyası ve Bazı Gözlemler. [1. bs.] (İstanbul: Boğaziçi Üniversitesi, 1982), 72-74.

3 Dr. Joseph Zanni'den sonra Avrupa'da kimya doktorası yapan diğer Türkler: Halil Edhem Eldem (Ph.D., Universität Bern) ve Mehmet Arif Beylikçi'dir (Ph.D., Friedrichs-Universität Wittenberg-Halle). Sözü edilen çizelgede yer almayan İstanbullu "Mühendis Kimyager" Kiryako Singros'un da aynı yıllarda Zürih Üniversitesi’nde doktora 
Merzifon Anadolu Koleji'nin tarihçesi üzerine sürdürdüğümüz araştırmada, okulun kimya öğretmeni Yuannis (يو انس)/Yani (يانى) Gavriil Statiropulos'un ${ }^{4}$ Yale Üniversitesi'nde (New Haven, Connecticut, ABD) 1905 yılında kimya doktorası yaptığını saptadık. Böylece, Dr. Yani G. Statiropulos, tarih sıralamasına göre, yurtdışında kimya doktorası yapan Türkler arasında dördüncü (ya da beşinci) ve Amerika'da kimya doktorası yapan ilk kişi olmaktadır. ${ }^{5}$

Kayseri'nin Talas bucağında 1875 yılında doğan Yani Gavriil Statiropulos, ${ }^{6}$ ilköğrenimini Talas Amerikan Okullarında tamamladıktan sonra, Merzifon Amerikan Anadolu Koleji'nden (Anatolia College) 1899 yılında B.A. derecesiyle mezun olmuştur. Anadolu Koleji'nin yönetimi tarafından 1902 yılında Sheffield Scientific School'a (New Haven, CT) gönderilen Yani Statiropulos, daha sonra Yale Üniversitesi'nde kimya öğrenimine başlayarak, 1904'de Bilim Uzmanı (M.Sc.) ve 1905 yılında Kimya Doktoru (Ph.D.) derecelerini almayı başarmıştır. Organik Kimya Araştırmaları ${ }^{7}$ konulu doktora tezini Prof. Dr. Henry Lord Wheeler'in yanında tamamlayan Yani G. Statiropulos'un Yale Üniversitesi'nin kayıtlarında memleketi: (Joannes G. Statiropoulos) “Caesaria [Kayseri], Turkey” olarak gösterilmiştir.

Türkiye'ye 1905 yılında dönen Dr. Statiropulos - Maarif Nezareti tarafından yüksek öğretim kurumu olarak tanınan - Anadolu Koleji'nde Kimya Profesörü olarak görev yapmıştır. ${ }^{8}$ Merzifon'dan 1913 yaz dönemi sonunda ayrılarak ABD’ne yerleşen Yani Statiropulos, New York ve New Jersey eyaletlerinde sanayi kuruluşlarında kimyager olarak çalıştı. Sınai Kimya Derneği (Londra, Society for Chemical Industry) üyesi olan Dr. Yani G. Statiropulos 1971 yılında Amerika' da ölmüştür. ${ }^{9}$

yaptığı anlaşılmaktadır (bkz. Emre Dölen, Türkiye'de Analitik Kimyanın Öncülerinden Kimyager Dr.Phil. Mehmed Arif Beylikçi (1865-1942) (İstanbul: Türkiye Kimya Derneği Yayınları, 2019), 1-6). Kyriakos L. Syngros, 1891'de Eidgenössischer Polytechnikum Zürich'den “teknik kimyager” olarak mezun olduktan sonra, 1892 'de Über die Verbindungen des Hydroxylamins mit Metallcarbonaten (Ph.D., Universität Zürich) başlıklı tezini tamamlayarak kimya doktoru olmuştur. Bu durumda, Dr. Kiriakos Singros Avrupa'da kimya doktorası yapan Türkler arasında dördüncü kişi sayılmalıdır, zira, Osmanlı uyruğunda olanlar eğitim gördükleri yabancı ülkelerde, ayrım yapılmadan "Türk" olarak nitelendirilmişlerdir.

4 Yani Gavriil Statiropulos'un adı: Yuannis/Yannis, Ioannis/Ioannes, Joannes, John; göbekadı: Gabriel; soyadı:

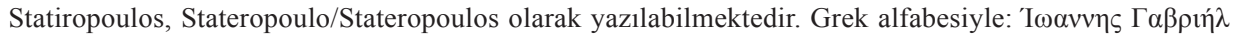
$\Sigma \tau \alpha \tau \eta \rho o ́ \pi о v \lambda o \varsigma$. Yuannis/Yani Statiropulos’un adının Arap harfleriyle yazımı dönemin belgelerinden alınmıştır.

5 Y.G. Statiropulos'un tezi İngilizce, diğer tezler ise Almanca olarak hazırlanmıştır.

6 Joannes Gabriel Stateropoulos adına düzenlenen 12.09.1918 tarihli askerlik belgesinde doğum tarihi 22 Şubat.1875 olarak gösterilmiştir: "Joannes Gabriel Stateropoulos. U.S., World War I Draft Registration Card, 1761-5029,” erişim 30.11.2019, https://search.ancestry.com/cgi-bin/sse. dll? indiv $=1 \& \mathrm{dbid}=6482 \& \mathrm{~h}=32839341 \& \mathrm{tid}=\& \mathrm{pid}=\&$ usePUB $=$ true \&_phsrc $=$ hdL147\&_phstart=successSource

7 Joannes Gabriel Statiropoulos, "Researches in Organic Chemistry" (PhD diss., Yale University, 1905). Tezin bir bölümü makale olarak yayımlanmıştır: bkz. Henry L. Wheeler, and Joannes G. Statiropoulos. "On Some Urazole and Imidothiobiazoline Derivatves," American Chemical Journal 34, 2 (1905): 117-132.

8 Prof.Dr.chem. Y. Statiropulos'un Anadolu Koleji'nde ayrıca fizik ve jeoloji dersleri de verdiği bilinmektedir.

9 John G. Stateropoulos, ölüm tarihi: 16 Aralık 1971, Bergen County, NJ. Bkz. "John G. Stateropoulos," New Jersey Death Index 1901-2017, erişim 30.11.2019, https://search.ancestry.com/cgi-bin/sse. dll indiv $=1 \&$ dbid $=3693 \&$ h $=59599551 \&$ tid $=\&$ pid $=\&$ usePUB $=$ true $\& \_$phsrc $=$hdL149\&_phstart $=$successSource 


\section{KAYNAKÇA / BIBLIOGRAPHY}

\section{Basılı Kaynaklar / Printed Sources}

Dölen, Emre. "Prof.Dr. Remziye Hisar'ın Anıları ve Görüşlerini İçeren Bir Kitap Hakkında Düşünce ve Katkılar." Osmanlı Bilimi Araştırmaları 20, 2 (2019): 133-145.

Dölen, Emre. Türkiye'de Analitik Kimyanın Öncülerinden Kimyager Dr.Phil. Mehmed Arif Beylikçi (18651942). İstanbul: Türkiye Kimya Derneği Yayınları, 2019.

İnönü, Erdal. 1923-1966 Dönemi Türkiye Kimya Araştırmaları Bibliyografyası ve Bazı Gözlemler, [1. bs.]. İstanbul: Boğaziçi Üniversitesi, 1982.

Statiropoulos, Joannes Gabriel. "Researches in Organic Chemistry.” PhD diss., Yale University, 1905.

Wheeler, Henry L., and Joannes G. Statiropoulos. "On Some Urazole and Imidothiobiazoline Derivatves." American Chemical Journal 34, 2 (1905): 117-132.

\section{Elektronik Kaynaklar / Electronic Sources}

“Joannes Gabriel Stateropoulos. U.S., World War I Draft Registration Card, 1761-5029.” Erişim 30.11.2019. https://search.ancestry.com/cgi-bin/sse.dll?indiv=1\&dbid=6482\&h=32839341\&tid=\&pid=\&usePUB=true\&_ phsrc $=$ hdL147\&_phstart=successSource

“John G. Stateropoulos.” New Jersey Death Index 1901-2017. Erişim 30.11.2019. https://search.ancestry. com $/$ cgi-bin/sse.dll $?$ indiv $=1 \&$ dbid $=3693 \&$ h $=59599551 \&$ tid $=\&$ pid $=\& u s e P U B=$ true\&_phsrc $=$ hdL $149 \&$ phstart=successSource 
